\title{
Colonial Voice Reinterpreted: A Readers Theatre Presentation
}

\author{
Jillian Thiele \& David Thiele
}

Pacific Adventist University

\begin{abstract}
Father and daughter inhabit the same space but interpret it differently. A colonial and a present-day educator see Papua New Guinea life through new lenses - the curriculum and the academic goals; students with new ambitions and diverse lifestyle issues; family and the extended wantok system; all factors affecting one's world view.
\end{abstract}

$\mathbf{F}$ ather: It is 1948 and my family and I have just arrived in Rabaul, East New Britain, after sailing, from Vailioa Training School in Samoa. My name is Hugh Dickins and I am a missionary educator for the Seventh-day Adventist church. ${ }^{1}$

What a contrast from Samoa! I left pristine beaches, polite people and clean villages, and now I am in a war zone. What a mess! The few standing buildings are pock-marked by bullets. Most houses have been bombed. Craters spot the landscape. The junk from the war is scattered everywhere. The war has actually just finished.

I have come to New Guinea to convert the natives, civilize them and educate them. And we really are going to be starting from nothing. They will need to be told about hygiene. Man, they stink! Then I will teach them to wear decent clothes. A cloth around their middle is not enough.

It is not just dress - its everything. The carvings and art work are pornographic and the dances just disgusting and the whole culture is all about sex and violence; grotesque.

Local Observer: Look that white man! He is walking fast; he's wearing so many clothes; doesn't he understand the weather? It is hot here. He needs to walk slowly to conserve energy. He'd be better off, just wearing a lap lap. The man smells sickly sweet from that “soap” he uses. Doesn't he know that that sweet smell brings mosquitoes? My pig grease keeps the mossies away. These white men have no idea how to live in our place.

Father: I am struggling with the fact that men want to hold my hand if they want to talk seriously with me. That was a shock the first time it happened. At least my wife will be able to avoid some of these shocks: there is a big enough expatriate community here that she won't have to have much contact with the natives at all. She can live in a social ghetto.

This country is completely undeveloped. The natives are living as they have done for thousands of years. Their housing is still made bush material thatch. There is plenty of opportunity for anyone with a bit of initiative. Business people can get rich here, but the natives don't seem to have any head for business. They make reasonable workers - with close supervision, but without expatriates the country will just remain in the stone-age. So

\footnotetext{
${ }^{1}$ Disclaimer: The form of this paper is biographical and autobiographical. It is important to note that this is not strictly correct for the content. Although much of content regarding my father is accurate to my memories of him, I have also deliberately deviated from strict accuracy to use him (as in the second half of the paper, myself) as a representative figure. Some of the attitudes attributed to him here, as a representative figure were, in fact, repugnant to him as an individual. However, the figure presented here in the form of my father is typical of many who worked in Papua New Guinea contemporary to him.
} 
there are plenty of expatriates here at the moment: planters, traders, soldiers, police, publicservants. I'm hardly alone either: there are dozens of other church missionaries.

Local Observer: The white men certainly know how to yell. The boss man wants everyone to hurry and work. He keeps looking at his watch as though it has some magic. He reckons he knows all about gardens, planting, and harvesting. The poor soil will never cope if he keeps planting all the new plants. Doesn't he know we plant enough for our clan and no more! What will he do with all the harvest? The people don’t need it!

Father: We had a pretty good house in Samoa, but it is different here. I've found a slab of fairly complete concrete and am in the process of building a black tar paper house. It's the best that can be done at the moment. There will be an attached cook house, an outside pit toilet. Water will have to be hauled from the improvised tanks. It will be tough, especially for my 'English lady' wife. And reliable power? That'll be the day! We will have to use kerosene lamps. However, there are some advantages we wouldn’t have in Australia: a garden boy to help with the yard and garden and a house "meri" to help inside the house. Native labour is cheap-even if it is pretty difficult to find reliable honest workers.

Local Observer: Look at the white ladies! Don't they work! Don't they know they will be hungry if they do not plant gardens for the dry season?

Father: It's 1952 and we have just come back from our first furlough. We soon discovered how much living in New Guinea has changed us. Most of my work is carried out in Pidgin English and good Pidgin is basically swearing in proper English. I had to censor myself all the time while we were in Australia. Mail comes so irregularly that we felt so out of touch with Australian politics and even the change of fashions. I'm sure people must have picked us as missionaries from a hundred paces!

I've become used to being called 'master' by the natives. Here the natives jump at my command. That doesn't happen in Australia. It's like living in two different worlds. We try to keep our home "Australian" as much as possible. It would be terrible to "go native" the way some expatriates have. I can't image inviting any of the natives home for a meal. They'd be uncomfortable and my wife would not know how to relate to them. She hasn't had to learn more than the most basic Pidgin.

Local observer: Don't the white ladies like our wives? They never talk to them. The men try to communicate with pidgin but wives, they only know English.

Father: It hasn't taken long for me to be considered the 'big man'. I can be very authoritative and dogmatic in this environment. I called the native 'boys' and the women 'meris' regardless of their age, experience or wisdom. They are very simple people - like children in lots of ways.

I have been sent to serve as a liaison officer between the church and the Government education department. One of my prime purposes is to re-open the Church primary schools that had been destroyed during the war. I have to find teachers, re-equip the schools and provide the necessary resources. I am considered well equipped for the task with a Diploma of Primary Teaching.

Local Observer: Look at the white man! He thinks his schooling in Australia made him ready for his work in New Guinea. He has no idea what he will be facing. He has no idea of the challenges. 
Father: What am I going to do? The war has completely destroyed the education system we were already starting in the 30s. Now there are not enough teachers to fill the ever expanding number of church primary schools, which are scattered from island to island all through the Bismarck Sea from Manus down to the Solomons. How am I going to find teachers, produce resources and build schools? This was never part of my educational training.

Local Observer: I told the master the other day that he should travel by boat from island to island assisting the schools and churches. I am a boat mechanic so I can travel with him.

Father: I have struggled to find a solution. With much prayer, I think I know the answer. I will take the elite students who had completed a grade two and arranged for them to embark on a year's intensive training at Jones Missionary College. On graduation, the students will return to their villages and teach school.

Local Observer: Master is a good man; he wants to help us even though there is so much about us he doesn't understand.

Father: It is now 1958 and I have been in New Guinea for ten years. I am not as naive as I was when I first arrived. Thank goodness the whites are in leadership and management positions. The natives only work if there is some kind of incentive. I refuse to use the whip but I understand why some use physical punishment and build gaols on their properties. All supplies are under lock and key. You can't trust the natives not to steal. When they get drunk, they beat their wives and kids.

Local Observer: I wish the white man knew that we are not stealing; we are just spreading the cargo to our wantoks. The white man doesn't need all his tools; they would be very handy in the village. He rewards his good workers by giving them booze and punishes them when they get drunk. He gets angry at us when we beat our wives, but he leaves his wife and travels away for weeks at a time and leaves his wife at home with no male protection. He calls us irresponsible!

Father: One of the things that frustrates me most of all here is the attitude to time. It just doesn't seem to matter at all. No-one comes to anything on time. No one prepares for anything until the last moment. Nothing is ever in short supply: there is either plenty or none! Even the obvious sweep of history escapes their notice. A native asked me recently if either I or my father had met Jesus when he was on earth. Two thousand years or two generations! There's no difference.

Local Observer: Master is funny sometimes. He talks about bad things that could happen. Doesn't he realize that he could be reliving the good things that happened in the past! He worries about things happening on time-as though he has something more important to do as soon as any event is finished. How can he enjoy the moment and savour the event with an attitude like that! The important thing is that things happen, not that they happen on time. Special events are to be enjoyed, not timed. Master gets frustrated with us spending time 'storying'. He has trouble with our ideal of 'Gutpela sindaun'. We like to sit down in peace, relaxing, eating and enjoying each other’s company. This is what life is all about!

Father: It is now 1960. I look back over the last twelve years. They were difficult years; balancing the support for teachers and training new educators. I am thrilled that we have 
achieved so much. I split my 'home' time between home in Rabaul and Jones Missionary College, at Kambubu, 80 miles from Rabaul.

Life at the school is very basic and primitive. The students live in thatched houses, work long hours in the gardens or on the copra plantation; wash and do their laundry down in the creek, eat garden products twice a day and study by kerosene lamps. When they graduate after 12 months, they are handed a box of chalk, a tin of blackboard paint and a teacher's manual which tells them what is to be taught for each lesson for every day for each class. The manual even includes examples of how to illustrate the blackboard and what homework activities the students ought to complete each night. They need very detailed instructions or the schools simply don't work. I wrote most of those teacher manuals. It was hard work but it has made a real improvement in the schools.

Our own children attend the local 'A' (Australian School). They could not possibly join the 'natives' at their schools. The content is based on the NSW curriculum. We are going to have to send the older children off to boarding school. We want them to be 'Australians”!

Local Observer: Master has a good family. On the boat, we 'story' for hours. His children play with our children but our children never go inside his house.

Father: It is 1966 and we have been transferred again. First it was from Rabaul to Lae, and now from Lae to Goroka in the highlands of New Guinea. I haven't been a ship's captain for years. Now it's all four-wheel driving up into the highlands! Sometimes I'll be flown into isolated rural area and walk for days or even weeks to even more isolated villages dropping off educational and medical supplies to teachers and health workers. On those treks, I preach every night, conduct baptisms, dedicate babies and even bury the dead!

I am the first white person many villagers have seen. When one of my younger daughters turned 13, I promised her a 'walkabout'. On the weeks' long walkabout, the local people were very interested in this white girl; the locals were keen to touch Jillian and play with her blond hair. One chief asked permission to marry her; he offered me 14 pigs for privilege. I declined!

My work focus up here is still education but now it's high schools. The church has built its first high school here at Goroka. Now . . . to train secondary teachers! It's exciting that the church work is ever expanding. But we are hampered by the lack of an effective communication system, good roads and cleared airstrips.

Traditional social and cultural attitudes are still a problem. Men are very much in charge of their wives; wife beating is terribly common. The colonial authorities do what they can but with little co-operation from the natives. The issue just isn't important to them.

Local Observer: Doesn't the master know that we purchased our wives with bride price. Men have to teach the women who is the boss; they will never learn otherwise!

Father: The natives here have no sense of "nation". Their loyalty is to their "place" and their "wantoks". Wantokism! What a blight on the country! Clan loyalty encourages fraud, theft, vandalism, tribal fighting and payback killings. The clan does not only consist of people, but of people that have died and those that had not been born. Keeping the spirits of the dead happy is seen as the key to having a happy village. The concept of sorcery and witchcraft pervades the whole culture. People are afraid of the spirits and the possibility of a curse. Huge feasts are frequently organised just to keep the spirits happy. The clan is run by a 'big man' who seems to get everyone to do his work for him by bribing them with incredibly wasteful feasts and "singsings". 
Local Observer: How little the master knows! Without the clan I would be alone in the world among enemies. The clan gives me protection. The wantoks help me when I am in trouble; and guide me when I am doing wrong. Master talks about tribal fighting but we never fight the way the whites did with the Japanese. Their fighting was worse than ours. I just don't understand why master thinks the things we do are so bad and the things his people do are so good. It is just the opposite sometimes.

Father: It is now 1969 and it is time to leave New Guinea. I am pleased with what I have been able to achieve but disappointed with the many failures.

I haven't been able to do much to change the basic approach to polygamy. I have been teaching the natives that they should only have one wife as the bible commands, but in the highlands not too many want to listen to this. Marriages are signs of prestige and influence. The number of wives and children are a sign of wealth and prosperity. For this ever expanding community to survive, a large and plentiful garden and numbers of livestock are necessary. Since women do the gardening, the more wives means more food.

Local Observer: No one will respect me if I only have one wife. Reputation is all about the number of children, the size of the garden and the contribution to ceremonies.

Father: Another problem area has been the basic understanding of religion. Much of the theology I had learnt at College seemed irrelevant in New Guinea.

Daughter: The year is 1993 and I have just arrived in Rabaul from New Plymouth in New Zealand. My name is Jillian Thiele. I am the third daughter of Hugh Dickins and my husband and I are under appointment to Sonoma Adventist College. It has been 23 years since I left New Guinea and I am excited to be going back to the land of my birth.

I just about cried when I saw the house we were going to live in at Sonoma. It was a long way short of the houses we had rented in Australia and New Zealand-but it was a permanent house made out of besser blocks, with electricity, running hot and cold water and an indoor toilet!

We do have a garden boy and a house girl—students who have been assignment by the college to our house for their "workline." But they are quickly becoming part of the family. These are bright, articulate, confident young people. Our garden boy is training to be a primary teacher and our house girl to be a secretary. We can talk about the state of the country and the wider world with them.

As much as possible we eat out of the local market. We wander freely through the Rabaul market. The national children often seem terrified of these strange white-skinned people but their parents are only amused by this. The market is a vast social network. Everyone is sitting, casually storying, waiting for customers.

Rabaul is a fairly small place and there are things we can't get, but our contract sees us going back to Australia every six months. There will be plenty of "retail therapy"-but only twice a year!

Local Observer: My name is Kenny Joe. I met Jillian in the park at Sonoma when I came to study there. She was trying to remember her pidgin from her childhood days. I could tell immediately that we could be good friends. She asked about my family and we shared information about shopping and where to buy local vegetables. Actually my grandfather worked with her father on the ships before Jillian was born. 
Jillian: There is no 'white ghetto' for us. There aren't many 'white people' at the college. Our friends are the mainly national academics. The college principal is an expatriate and has a Master's degree. My husband and I are working on our Masters but virtually everyone else has a bachelors' degree. The education standard has gone up since my father' day! All of our students have good grade 10 passes. It is still very rare for students to go to Grade 12 in PNG. They say it is easier to get in to Medicine in an Australian University than it is to get into Grade 11 in a PNG Secondary school!

Local Observer: Jillian and David invited me over to their home to have a meal and watch a video. Their garden boy and house girl were there as well. It was a fun evening!

Jillian: Culture show time again! We take every opportunity to see culture in action fascinating.

Local Observer: My name is Andrew Opis. I am a theology student. We are being taught to value our culture and express our Christianity in terms of our culture. Jesus is a Hagan man - like me!

Jillian: It is 1994 and the eruption of the twin volcanos has stretched our resources and our patience. The college became a refuge station for 3,000 refugees who had escaped from the volcano. Until tents and canvases arrived, the residents took the refugees into their homes. At one stage, we have 12 people living with us, and another 25 in the garage. The excitement soon turned to stress, as food was short, the water had to be rationed and the sulphur in the air affected my health.

Local Observer: My name is Elsie and my family have been living with the Thiele's for months. We lost everything. Jillian became so sick that she and the children had to leave. I am looking after her husband while his family is away.

Jillian: It is the year 2000 and we have transferred to Port Moresby-Pacific Adventist University. Here we really are among the elite! Some of the national lecturers have doctorates and we will have to up-grade our qualifications as well. The country is changing rapidly and the rate of change seems to be increasing! The government has adopted a policy of universal Grade 12 education for students progressing to college or university. PAU has just commenced its first Masters programme. The grandchildren of some of my father's workers are going to have Master's degrees. I don't think Dad could have ever imagined it!

My parents waited at least six months for mail; we have internet and phones. It is actually rare to find a PAU student who doesn't have a mobile phone-at least one! The university has computer labs but an increasing number of students have their own lap tops.

Local Observer: It was so much fun teaching Dr Thiele how to use a mobile phone.

Jillian: As a private institution, PAU charges relatively high fees. Many of our students come from affluent homes but there are still plenty who come from subsistence or settlement backgrounds. This is where the wantok system shows its worth. The entire extended family is involved in raising the fees for some of these students. It's not "every man for himself".

PAU is clearly a Papua New Guinean institution, but in some ways, very similar to schools in Australia. The dorms are well equipped with running water, 24 hours power, laundries and such like. A well serviced dining room caters to their food needs. The library is respectably stocked and in some areas is probably better than many schools in Australia. 
Research resources are supplemented with electronic data bases and e-books. The internet has provided access to an even greater variety of materials. When my students graduate they are familiar with all form of computer use; and are readily employed in schools, business, and hospitals all across the Pacific.

Local Observer: As a student at Pacific Adventist University, Dr Jillian Thiele marks all our assignments electronically. She is tough but fair.

Jillian: Some things haven't changed! Our children have gone to boarding school in Melbourne, just like my brother and sister did! We seriously considered keeping them here as the international school in Port Moresby has a world class reputation, but in the end, we opted for boarding school. Most of the students there are not Australians anymore.

More girls have access to schools these days. This is in line with Government policy but there is still gender disparity. Women in PNG are less likely to go to school, read or be in paid employment, more likely to suffer violence and poor health. Women are also at greater risk than men in PNG from the country's HIV/AIDS epidemic. Stated Government policy hasn't translated all that well into changing practice.

One thing which my parents were unconcerned about was law and order issues. The high electric fence around the compound makes us constantly aware of security. The crime rate in Moresby is horrific. However, we have found something really basic: if you treat people decently — with a modicum of human dignity - the majority of people will respond in kind. If we park our car down-town, we make a point of greeting the young men and women sitting around storying; make a fuss over the children they have with them and generally show ourselves to be friendly. Our car has never been broken into.

Local Observer: I am the security officer at Pacific Adventist University. The Thiele's are friends with everyone. I don't expect too many security issues with the family.

Jillian: PNG is a complicated anthropological puzzle. Some 95 percent of the people described themselves as Christians. Sometimes I think that 100 years of missions has made very little difference to the country, but I know that really isn't the case! Nationals themselves are struggling to find their footing in two worlds simultaneously. The elders in the village still think in terms of arranged marriages but our students at PAU find themselves in a vast "spousal supermarket' and are readily exposed through the media, to a completely different model of courtship and relationship.

If missionaries of my father's generation saw "bride price" as a terrible thing-a man buying a women-I recognize that it is a gift binding two families together. However, I have also had a male student tell me that bride price is a terrible thing because it makes the women feel that she is worth something when in actual fact, a woman is worth "nothing"! So which of these three perceptions of the practice is correct? And what are we to make of the serious inflating of bride price in recent years - which does make it seem more of a commercial activity. Bride price for a university educated girl can be hundreds of thousands of kina. Is this why some of our highly educated male students have wives who never even finished primary school?

Western-style formal education has been in PNG for a long time but education has not necessarily changed attitudes to the spirits. Many of the students still wear 'good luck charms'. Some can give perfectly adequate scientific explanations in exams but nevertheless look for the "real" reason for illness and misfortune in the activity of the spirits. Even at PAU there are no unexplained tragedies. Bad things are caused by the malevolent activities of sorcerers. The killing of suspected sorcerers remains a staple of news reporting in PNG. 
Reciprocity remains a central social norm. I am sometimes frustrated by my inability to help some students who do not want to be in a position of owing a debt they could not repay. Some students become members of our extended family, and extremely careful to repay any kindness in kind.

Local Observer: My name is Tupi Alova. The Thieles have been "mum" and "dad" to me since I was in High School. When I became a PAU student it was initially a little bit difficult. Mum Thiele told me I could come up to the house and use her washing machine but I felt uncomfortable. I didn't want to take advantage of them or being in a position of owning them for kindness shown. But I have discovered that I can sweep the floors and fold her washing while my washing is being done, so I am OK with use their washing machine now.

Jillian: There are still plenty of frustrations for an expatriate here. But building on the foundation laid by men like my father, it is possible to see the differences from our cultural background as part of a rich cultural tapestry. This is not a primitive culture but a rich elaborate set of traditions which evolved to meet the distinctive social needs of this amazing country.

Local Observer: My name is Bryan Paul. I am the art teacher at Pacific Adventist University. Jillian was not only my boss as Dean of the School of Arts and Humanities, we are colleagues and friends. We have sat and talked in one another's offices and eaten in one another's homes. I have known the Dickins' family since I was a child. My father worked with Jillian's father. Like Jillian, her father was passionate about education and very professional in his work. He clearly had a deep commitment to the people of New Guinea. But my dad never visited the Dickins' home, and was never introduced to Mrs Dickins. Work and home lives were kept very separate. How things have changed in fifty years!

Conclusion: Jillian: My father and I have spent most of our working lives as educators for the Seventh-day Adventist church in the PNG. As an experienced teacher, my dad came in 1948 during the colonial administration to resurrect a destroyed education system, train teachers and design an appropriate curriculum. As a trained professional educator I arrived in 1993 with the aim to train primary and secondary teachers in the best available learning and teaching practices.

We both wished to change and improve the educational facilities; both tried to understand our students and provide a relevant and appropriate curriculum. My father came from a different Australia to me-the Australia of the "white Australia Policy" and the "white man's burden". Anthropology was in its infancy and appreciation of "primitive" culture virtually non-existent. Not only so, but we both came to radically different Papua New Guineas. We both lived in the same place but given the changes in time, education and development, our views and actions have been different.

\section{Works Cited}

Alova, Tupi. (2011). Interview between Tupi Alova, an Education students and Jillian Thiele, Affiliation Officer at Pacific Adventist University. 
Bartle, Neville. (2005). Death, Witchcraft and the Spirit World in the Highlands of Papua New Guinea. Point 29. Goroka, PNG: Melanesian Institute of Pastoral and SocioEconomic Service.

Bellwood, P. (1978). Man's Conquest of the Pacific. New York, NY: Oxford University Press.

Chao, Sr M. John Paul. (1984). 'Leadership’. In An Introduction to Melanesian Cultures. D. Whiteman, ed. Point Series No. 5. Goroka, PNG: Melanesian Institute, pp 127 - 148.

Editorial - PNG’S ‘Millennium Goals far from reality.' (10 Sept, 2010). The National.

Fugmann, Gernot. (1984). 'Salvation in Melanesian Religions.' In An Introduction to Melanesian Religions. Ennio Mantovani (ed). Point Series No. 6. Goroka, PNG: Melanesian Institute; pp 279 - 295.

Institute of Medical Research Study, cited in Amnesty International. (2006). Papua New Guinea:Violence Against Women: Not Inevitable, Never Acceptable! Available at: http://amnestry.org/en/library/info/ASA34/002/2006, p. 5

Joe, Kenny (2004). Interview between Kenny Joe, business student and David Thiele at Sonoma Adventist College.

Law Reform Commission (1996). Final Report on Domestic Violence, Report 14. Cited in UNICEF Papua New Guinea (2008). Child Protection Situational Analysis 2008. Port Moresby: UNICEF, p. 1.

Lawrence, P. \& Meggitt, M. J. (eds). (1965). Gods, Ghosts and Men in Melanesia. Melbourne, VIC: Oxford University Press.

Mantovani, Ennio. (1984). 'Celebrations of Cosmic Renewal.' In An Introduction to Melanesian Religions. E. Mantovani (ed) Point Series No 6. Goroka, PNG: Melanesian Institute: pp 147 - 168.

Noho, B. (2010). 'PNG Lags in Progress towards Millennium Goals: Widespread corruption blamed”. Pacific Island Report: Post-Courier.

Opis, A. (2000). Interview between Andrew Opis, theology student and David Thiele, Dean of the School of Theology at Pacific Adventist University.

Sinebare, Musawe, (April 4, 2011 ). NG V2050: Allegiance to PNG vs. allegiance to tribal communities'. Sunday Chronicle.

Swain, T. \& Trompf, G. (1995). The Religions of Oceania. London: Routledge.

Trompf, G. W. (1994). Payback. Cambridge: Cambridge University Press.

Trompf, G. W. (1991). Melanesian Religions. Cambridge: Cambridge University Press.

Whiteman, D. (1984). Melanesians and Missionaries. Pasadena, CA: William Carey Library. 
Biography: Drs David and Jillian Thiele have spent nearly twenty years as missionary educators in Papua New Guinea, first at Sonoma Adventist College and then at Pacific Adventist University. David's expertise, as current Dean of the School of Theology, is in the area of theology and Biblical studies. Jillian, a daughter of long-term missionaries, is currently the Affiliation Officer at the university with the primary role of moderating the academic quality on the various campuses. Her academic expertise is in Education and applied linguistics. 